\title{
Chimpanzee handedness revisited: 55 years since Finch (1941)
}

\author{
WILLIAM D. HOPKINS \\ Emory University, Atlanta, Georgia
}

\begin{abstract}
Chimpanzees and other great apes have long held the fascination of psychologists because of their morphological and behavioral similarities to humans. This paper describes the historical interest in studies on chimpanzee handedness and reviews current findings. Data are presented which suggest that transient changes in posture result in the transient expression of right-handedness in chimpanzees. The role of tool use as an evolutionary mechanism underlying the expression of right-handedness is challenged. Rather, emphasis is placed on the role of bimanual feeding as a behavioral adaptation for the expression of handedness. Suggestions for further research on the nature of nonhuman primate handedness are made in light of these findings.
\end{abstract}

Approximately $85 \%$ to $90 \%$ of humans are right-handed (Annett, 1985). Moreover, 98\% of right-handed individuals are left-hemisphere dominant for linguistic functions (Rasmussen \& Milner, 1977). Thus, right-handedness and left-hemisphere specializations for linguistic functions are correlated functions. The concept of hemispheric specialization dates back to the early studies of Dax, Wernicke, and Broca, and one topic of interest that emerged from these early studies was whether or not animals possessed similar specializations of the left and right cerebral hemispheres (see Harris, 1993, for review). Of particular interest was whether nonhuman primates exhibited handedness, and chimpanzees and other great apes were often discussed as interesting subjects because of their physical and morphological similarity to humans. However, most reports of handedness in chimpanzees and other great apes were anecdotal (Yerkes, 1927).

In 1941, Glenn Finch of the Yerkes Primate Center, then located in Orange Park, Florida, reported in Science the first systematic study on handedness in 30 chimpanzees. The study included 26 adults and 4 adolescents and utilized four measures of hand preference, including (1) pulling in a string with attached food, (2) picking up 10 pieces of food spaced at 3-in. intervals, (3) picking up food when displacing a metal object covering it, and (4) selecting in-

This investigation was supported in part by National Institutes of Health Grant RR-00165 from the National Center for Research Resources to the Yerkes Regional Primate Research Center. Additional support was provided by the National Institute of Neurological Disorders and Stroke Grant NS-29574 to the author. The Yerkes Primate Center is fully accredited by the American Association for Accreditation of Laboratory Animal Care. Thanks are extended to the animal resources staff of the Yerkes Primate Center for the supportive services they provided to Allyson Bennett, Stacy Bales, Lisa Parr, Van Dao, Charles Hyatt, and David Leavens for facilitating data collection and analysis, and to Michael Corballis and two anonymous reviewers for their comments on an earlier draft of this paper. Correspondence and reprint requests should be addressed to W. D. Hopkins, Division of Behavioral Biology, Yerkes Regional Primate Research Center of Emory University, Atlanta, GA 30322 (e-mail: Ircbh@rmy,emory.edu). dividual pieces of food presented on a board. A total of 200 trials were presented to each subject and handedness measure. Subjects using one hand on at least $80 \%$ of the overall responses were classified as either left- or righthanded. All other subjects were considered ambidextrous. No attempt was made to dissociate hand preference in relation to each measure. In total, 14 subjects were classified as left-handed, 11 as right-handed, and 5 as ambidextrous. Finch (1941) concluded that individual chimpanzees exhibited hand preference but did not exhibit populationlevel right-handedness, a pattern indicative of human handedness. Nonetheless, Finch cautioned that "the present work does not pretend to explore more than a rather narrowly limited aspect of chimpanzee lateral organization" (p. 118).

Between 1941 and 1987, there were very few reports on handedness in chimpanzees or in other great apes. Most of the reports were anecdotal (Ferster, 1957; Glaser, 1971), presented little or no data (Dimond \& Harries, 1984; O'Neil, Stratton, Ingersoll, \& Fouts, 1978), or involved very few subjects, thus limiting generalization of their findings (Brésard \& Bresson, 1983; Chorazyna, 1976; Grzimek, 1949; Robinson, 1979; Welles, 1976). In contrast, there were a considerable number of hand- or pawpreference experiments conducted in monkeys, cats, and rodents (see Bradshaw \& Rogers, 1993; Warren, 1980, for reviews). Finch's study remained one of the few systematic studies reported in chimpanzees throughout this period of time.

Despite the fact that few studies were conducted on hand preferences in chimpanzees for the better part of 50 years, interest in further inquiry was repeatedly expressed in the scientific community (see Geschwind \& Galaburda, 1987; Steklis \& Raleigh, 1979). In particular, reports of tool use in wild chimpanzees (Goodall, 1970, 1986), the plethora of interest surrounding ape-language experiments (Gardner \& Gardner, 1968; Premack, 1970; Rumbaugh, 1977; Savage-Rumbaugh, 1986), and evidence of neuroanatomical asymmetries (Yeni-Komshian \& Benson, 1976) 
all stimulated interest in the topic of handedness and hemispheric specialization as a whole in animals (Geschwind \& Galaburda, 1987).

Notwithstanding this, the prevailing view that chimpanzees and other nonhuman primates lacked populationlevel handedness resulted in the establishment of several evolutionary theories of human handedness that were linked to such species-specific human traits as bipedalism, object manipulation, and the manufacture and use of tools (Bradshaw \& Rogers, 1993; Hellige, 1993). Paramount to nearly every evolutionary theory of handedness was the emergence of bipedalism in early hominids. In all of these evolutionary scenarios, handedness at a population level evolved after bipedalism emerged as a human species-specific trait. Bipedalism resulted in a complete freeing of the hands from locomotor functions, allowing them to be used in a coordinated fashion to manufacture and use tools (Corballis, 1992; Frost, 1980; Kimura, 1979), for purposes of gestural communication (Hewes, 1973), or for throwing objects at prey or predators (Calvin, 1983). The exception is MacNeilage, Studdert-Kennedy, and Lindblom's (1987) "postural origins" theory of handedness. The postural origins theory states that in more primitive, arboreal primate species, a left-hand population bias exists for visually guided reaching in conjunction with a right-sided asymmetry for postural control. For more recently evolved terrestrial primates, such as chimpanzees and other great apes, rather than providing postural support, the right hand became the preferred hand for manipulation, while the left hand retained its specialization for visually guided reaching.

Research on nonhuman primate handedness was rekindled after MacNeilage et al. (1987) published their "postural origins" theory of handedness. The postural origins theory states that in more primitive, arboreal primate species, a left-hand population bias exists for visually guided reaching in conjunction with a right-sided asymmetry for postural control. For terrestrial primates, such as chimpanzees, rather than providing postural support, the right hand became the preferred hand for manipulation, while the left hand retained its specialization for visually guided reaching.

Since 1987 , several published hand-preference studies in captive and wild populations have appeared in the scientific literature. Most of these studies are directly relevant to the aforementioned evolutionary theories of handedness. Therefore, evaluation of these models seems appropriate at this time. In addition, the recent studies in chimpanzees, which have assessed hand preference using more elaborate and sophisticated measures, have studied a wider range of behaviors indicative of chimpanzee lateral organization, a recommendation from Finch's (1941) earlier work. For the purposes of this review, this paper will focus on chimpanzee hand-preference studies published since MacNeilage et al.'s (1987) review paper on nonhuman primate handedness. Moreover, to simplify data presentation, only those published studies with sample sizes of 10 or more subjects will be discussed. Studies of perceptual and cognitive asymmetries are not in- cluded in this review. Where possible, I will discuss related findings in other species of great apes, including humans, in order to draw comparisons between them.

\section{UNIMANUAL MEASURES}

\section{Postural Constraints on Hand Use}

Reaching. The initial observations by Finch regarding hand preference and simple reaching in chimpanzees have been confirmed by several investigators (see Hopkins \& Morris, 1993; Marchant \& McGrew, 1991, for reviews). Investigations of quadrupedal reaching usually involve placement of food in the subjects' enclosure and recording which hand they use to reach for and pick up the pieces of food. The results in nearly every study reveal equal numbers of subjects that were left-handed, right-handed, and without a preference (Christel, 1994; Hopkins, 1993; Hopkins, 1995b; Marchant, 1983; Marchant \& McGrew, 1996; Steiner, 1990; Tonooka \& Matsuzawa, 1995). This same finding has been reported in other great-ape species, including gorillas (Annett \& Annett, 1991; Olson, Ellis, \& Nadler, 1990), orangutans (Cunningham, Forsythe, \& Ward, 1989; Hopkins, 1993), and bonobos (Hopkins, Bennett, Bales, Lee, \& Ward, 1993; Hopkins \& de Waal, 1995).

Manipulating the subjects' posture by requiring them to reach for food from a bipedal rather than quadrupedal posture results in a shift toward greater preferential use of the right hand (Hopkins, 1993). Depicted in Figure 1 are the average percentages of right-hand use for quadrupedal and bipedal reaching in four species of great ape. ${ }^{1}$ These data have been derived from the original publications of Hopkins (1993), Hopkins, Bennett, et al. (1993), and Olson et al. (1990). As can be seen, the shift in hand preference is dramatic enough to result in a significant population-level expression of right-handedness. Moreover, the overall pattern of hand preference and posture is consistent between great ape species.

The results above involved comparisons made of reaching from a bipedal posture and of reaching from a

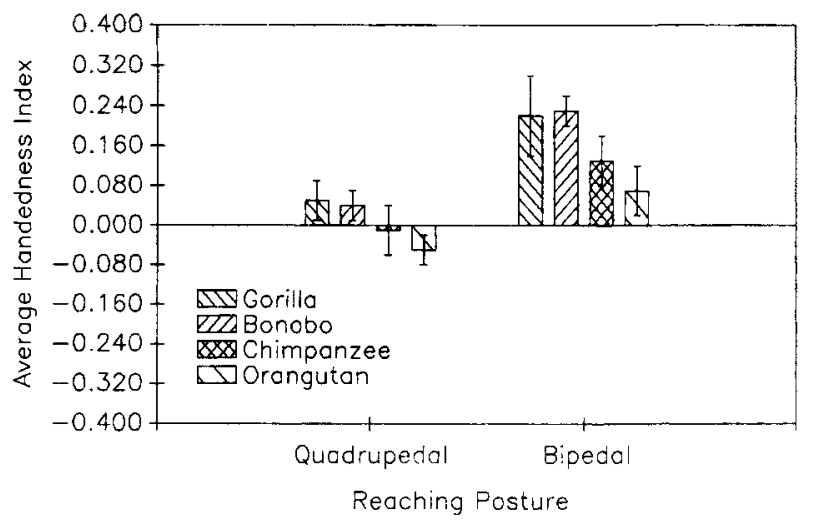

Figure 1. Average handedness index and standard error as a function of posture in gorillas, bonobos, chimpanzees, and orangutans. 
quadrupedal posture. Recently, Colell, Segarra, and Sabater-Pi (1995a) have reported data on hand use in 33 chimpanzees, 2 orangutans, and 2 bonobos when retrieving food from a quadrupedal posture and when retrieving food floating on the top of water in a moat surrounding the subjects' enclosure. Reaching into the moat to retrieve the food required that the subjects adopt and maintain a rather extreme and unstable posture while reaching for the food. For the simple reaching condition, there were 15 right-handed and 10 left-handed subjects. In contrast, when the condition involved reaching into the moat, there were 8 right-handed subjects and 1 left-handed subject. For the 9 subjects for which data were collected in both reaching conditions, the mean percentage of righthand use for quadrupedal reaching and reaching into the moat were 58.5 and 87.2 , a difference that was statistically significant.

Aimed throwing. Calvin (1983) has hypothesized that the neurophysiological and cognitive demands of throwing may have served as an important evolutionary precursor to handedness, tool use, and language processing in early hominids. Calvin (1983) argues that right-handed throwing evolved in humans as a result of the left hemisphere's specialization for planned sequential movements. With specific reference to right-handedness, a statistical majority of humans throw with their right hands (Healey, Liederman, \& Geschwind, 1986).

At the Yerkes Regional Primate Research Center, we have observed throwing by a number of chimpanzees. Typically, the chimpanzees throw at unfamiliar individuals or in frightening contexts such as when unfamiliar vehicles or people suddenly appear in close proximity to the home cage. The chimpanzees usually throw wet chow, feces, or objects in their cages at the strangers. As a means of testing Calvin's (1983) theory regarding handedness and throwing, we began, and continue, to take records of hand use when throwing is observed by any of the chimpanzees (see Hopkins, Bard, Jones, \& Bales, 1993, for a preliminary report). During each observed throwing bout, the posture of the chimpanzee is recorded as being either quadrupedal or bipedal. The hand used in a throw (left or right) and whether it was an underhand or overhand throw are also recorded.

To date, we have observed hand use and throwing in 44 chimpanzees. For 36 of these chimpanzees, we have recorded 8 or more instances of hand use and throwing. Of these 36 chimpanzees, 24 were categorized as righthanded, 10 as left-handed, and 2 as having no significant hand preference. This distribution differs significantly from chance $\left[\chi^{2}(2,34)=13.76, p<.01\right]$, with a population right-hand bias evident in the sample.

As in the reaching studies, posture proved to be an important factor in the expression of right-handed throwing. Nearly every chimpanzee that preferred to throw with its right hand threw from a bipedal posture. In contrast, chimpanzees that threw from a quadrupedal posture tended to throw with either the left or right hand. One other ob- servation should be noted. On nearly every occasion, the subject accurately hit the individual passerby with the projectile. This is by no means trivial, because it distinguishes aimed throwing from the random throwing that is observed when chimpanzees are displaying or during aggressive encounters (Goodall, 1986). In the only other report on handedness and throwing in chimpanzees, Marchant (1983) failed to report population hand biases in throwing. Marchant (1983) reported that there were 5 right-handed and 4 left-handed individuals; however, it is not clear whether aimed throwing was distinguished from throwing in the context of displaying or aggression.

\section{Manipulation}

Aruguete, Ely, and King (1992) examined hand preferences in 27 chimpanzees in touching and manipulating their faces, bodies, or the external environment. Overall, $61.4 \%$ of the unimanual responses directed toward the environment were made by the right hand, a percentage that deviates significantly from chance. No hand bias was found in actions directed toward the body or face, a finding at odds with at least one other report about ape behavior (Dimond \& Harries, 1984, but see Suarez \& Gallup, 1986). Of the 27 chimpanzees, 7 exhibited a righthand bias in environmental exploration, while only 1 displayed a left-hand bias; 19 failed to exhibit a significant hand bias.

Tonooka and Matsuzawa (1995) tested hand preferences in 80 chimpanzees by recording the hand used and the type of grip employed to retrieve raisins scattered in an empty test cage. In terms of hand preferences, 12 were classified as right-handed and 20 were classified as lefthanded; 48 had no preference. However, a significant relation was found between grip type and hand use. Imprecise precision grips, defined as those involving the thumb and side of the index finger, were observed significantly more often when food was picked up with the right rather than the left hand. This trend was evident in chimpanzees classified as being either right- or left-handed. In contrast, picking up food with the index and middle finger was observed significantly more often for left- as opposed to right-hand responses. In short, use of an imprecise precision grip was more prevalent when the reaching was done with the right rather than the left hand.

Jones-Engel and Bard (1996) similarly examined hand preference and grip type in 13 juvenile chimpanzees. They compared, among other things, hand preference in relation to precision and power grips. In terms of hand preference, 4 showed a left-hand preference, 3 showed a right-hand preference, and 6 exhibited no hand preference. Unlike Tonooka and Matsuzawa (1995), Jones-Engel and Bard failed to find greater use of imprecise precision grips when subjects used their right hands. In fact, power rather than precision grips were executed more rapidly by the right than the left hand. There was also a trend for the chimpanzees to retrieve small food items faster by using a precision grip with the left rather than the right hand. 


\section{BIMANUAL HAND USE MEASURES}

Bimanual handedness tasks are excellent measures of hemispheric specialization in humans for several reasons, including (1) their predictability of left-hemisphere specialization in linguistic functions, (2) the high correlation with self-reports of hand use, and (3) the requirement that the two hands perform different roles, one subordinate and one dominant. The early reports of bimanual hand use in chimpanzees were largely anecdotal and involved very few subjects (Brésard \& Bresson, 1983; Morris, Hopkins, \& Bolser-Gilmore, 1993). Such measures included painting (Glaser, 1971), tool use (Nishida \& Hiraiwa, 1982), and open-and-search tasks (Brésard \& Bresson, 1983; Marchant \& Steklis, 1986). More recently, systematic data have been reported on handedness for bimanual tasks, particularly in the use of tools by feral chimpanzees (Boesch, 1991; McGrew \& Marchant, 1992; Sugiyama, Fushimi, Sakura, \& Matsuzawa, 1993).

\section{Tool Use}

Several investigators have emphasized the role of tool use and praxic movements in the evolution of handedness in early hominids (Corballis, 1989, 1992; Frost, 1980; Kimura, 1979). Although a variety of nonhuman species exhibit forms of tool use (Beck, 1980), there is a general consensus that chimpanzees exceed all other animals (save humans) in the extent and the variability that they exhibit in tool use (see Goodall, 1986).

The results on hand preference and tool use in wild chimpanzees are described in Table 1. Boesch (1991) and Sugiyama et al. (1993) have both examined hand use in the nut-cracking behavior of chimpanzees. Nut-cracking behavior involves the use of an anvil and hammer which the apes use to open different types of nuts. Both Boesch (1991) and Sugiyama et al. define nut cracking as a bimanual task, because one hand is used to place the nut on the anvil and the other is used to pound the nut with the hammer. In both studies, the hand used to pound with the hammer was scored for hand preference. As can be seen, no significant population-level handedness was found in either sample of chimpanzees. Boesch's data hint at a possible age difference in hand use, with younger chimpanzees showing greater use of the right hand.

In contrast to nut-cracking, McGrew and Marchant (1992) examined hand use in termite fishing in 15 feral chimpanzees. Termite fishing has been well documented

\begin{tabular}{lrrrl} 
& Table 1 \\
& $\begin{array}{c}\text { Results of Studies on Hand Preference } \\
\text { and Tool Use in Chimpanzees }\end{array}$ \\
& \multicolumn{4}{c}{ Handedness } \\
\cline { 2 - 4 } \multicolumn{1}{c}{ Study } & \multicolumn{1}{c}{ Right } & Left & Ambidextrous & Subjects \\
\hline Boesch, 1991 & 19 & 21 & 1 & adults \\
& 15 & 6 & 5 & subadults \\
Sugiyama et al., 1993 & 9 & 8 & 1 & all \\
McGrew \& Marchant, 1992 & 6 & 5 & 4 & all \\
Total & 49 & 40 & 11 & \\
\hline
\end{tabular}

Note-Values represent frequencies in left- and right-hand use. in chimpanzees and involves the use of a stick or twig which is inserted into a hole on a termite mound. The chimpanzee must insert the stick or twig into the hole slowly so that the termites will attach themselves to the stick. The chimpanzee then must retract the stick to eat the termites that have attached to the stick. As with the nut-cracking studies, no significant population-level handedness was observed for this measure. Eight chimpanzees were classified as left-handed and 7 were classified as right-handed.

\section{Bimanual Foraging}

An assumption underlying the significance of asymmetrical bimanual manipulation is that tool use constituted the major selection feature for these praxic functions. However, bimanual asymmetries could have evolved from environmental demands unrelated to tool use. For example, Wundrum (1986) suggests that bimanual feeding and food processing rather than tool use may have served to select for handedness in bimanual coordination. There is some empirical support for this theory. Byrne and Byrne (1991) examined bimanual processing of five different food types in 44 feral gorillas. In that study, the active and supportive roles of the left and right hands during food processing was recorded for each food type. Although the effects were not extremely robust, there was a significant population bias for the gorillas to hold or grasp the food items with their left hands and to manipulate or process the food with their right hands. Fagot and Vauclair (1988) have reported similar results in a sample of 10 captive gorillas on a measure designed to elicit coordinated bimanual actions.

Recently, Hopkins and his colleagues have recorded hand use for bimanual feeding in 140 chimpanzees (Hopkins, 1994a) and 21 bonobos (Hopkins \& de Waal, 1995). Bimanual feeding was defined as feeding bouts in which the apes held extra food items with one hand and simultaneously fed with the opposite hand. The hand used for feeding was defined as the dominant hand. The overall distribution of subjects exhibiting a right, left, or ambiguous preference is depicted in Figure 2. As can be seen, in all four great ape species, a significant proportion of the subjects exhibited a right-hand bias in feeding.

To more specifically address the issue of coordinated bimanual hand use, Hopkins (1995a) tested 110 chimpanzees for hand use while extracting peanut butter from the inside of PVC tubes. This test required that the chimpanzees hold the tube with one hand while simultaneously extracting the peanut butter from the tube. Thus, the left and right hands had to work in a coordinated manner to efficiently remove the food. Overall, a significant population-level right-hand bias was found in this sample, with $67 \%$ of the lateralized subjects exhibiting righthand preferences.

Colell, Segarra, and Sabater-Pi (1995b) tested 24 chimpanzees on a series of manipulation tasks, one of which required 16 subjects to simultaneously hold a panel while extracting food from a small aperture. Thus, this task required coordinated bimanual actions. Overall, no signif- 


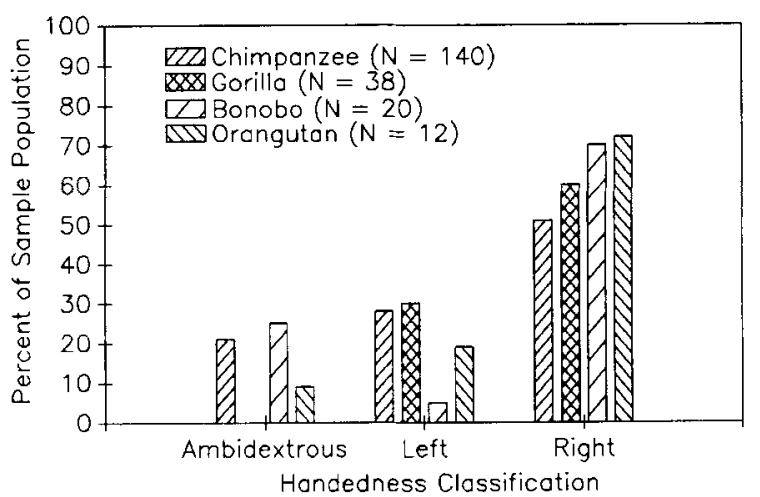

Figure 2. Distribution of ambidextrous, left-handed, and righthanded subjects for bimanual feeding as a function of species.

icant population bias was found, but, in the adult subjects, 6 preferred to hold with the left hand and remove the food with the right, while only 1 subject exhibited the opposite pattern of bimanual hand use. In contrast, in the juveniles, 7 preferred to hold with the right hand and reach with the left hand, while 1 preferred to hold with the left hand and reach with the right. The age differences in coordinated bimanual hand use are similar to those reported by Hopkins (1995a) and Ramsay and Weber (1986) in human infants.

\section{SUMMARY}

Current data on chimpanzee handedness suggest that Finch's (1941) conclusion regarding the absence of population-level handedness was premature. Consistent with other reports in nonhuman primate species (Ward \& Hopkins, 1993), handedness at a population level appears evident in chimpanzees, at least for some measures. On the basis of the available data obtained from great apes and other nonhuman primates, several tentative conclusions can be advanced regarding the evolution of handedness in humans.

\section{The Role of Posture}

Posture clearly influences the expression of hand preferences in chimpanzees and other great apes. This is evident from studies that have directly manipulated posture (e.g., bipedal vs. quadrupedal reaching) and studies in which bimanual activities have been recorded (e.g., feeding). For the bimanual measures, posture is indirectly manipulated because the left and right hands are needed to execute the desired action; the left and right hands cannot be engaged in any postural functions while subjects are engaged in the task. I believe that this makes bimanual measures of hand preference particularly appealing from a comparative perspective, because it allows for direct comparison with human handedness measures.

With respect to studies directly manipulating posture, the findings in great apes are not unique. Manipulating posture has been shown to influence strength and direction of hand preference in other nonhuman primate spe- cies, including prosimians (Ward, Milliken, \& Stafford, 1993), New World monkeys (King \& Landau, 1993; Roney \& King, 1993), and Old World monkeys (Fagot, Drea, \& Wallen, 1991). The findings from great apes differ from the monkey and prosimian results in one important way: apes are the only taxonomic family in which right-handedness is observed when reaching from a bipedal posture. In prosimians and monkeys, reaching from an erect or bipedal posture results in the expression of population left-handedness.

Why manipulation of posture influences the direction of hand preference remains unclear, but I believe there are at least three possible explanations. First, hand preferences for throwing as well as for bipedal reaching are transient, or, in the words of Ward et al. (1993), they represent state asymmetries. Bipedal locomotion is also a behavioral state and not a behavioral trait in great apes (Tuttle, 1986). It might be suggested that, with the evolution of bipedalism as a behavioral trait in early hominids, right-handedness evolved as a behavioral trait rather than being elicited by specific behavioral states.

Second, it may be that hand preferences elicited during bipedal reaching and throwing are due to asymmetries in posture rather than handedness per se. Heestand (1986) has reported that chimpanzees, orangutans, gorillas, and gibbons exhibit right-leading limb asymmetries when initiating locomotion. Thus, the apes fully support their body weight on their left sides in order to lead their locomotion with the opposite hands/arms. A related finding is the evidence that apes exhibit left-side cradling and carrying biases (Manning \& Chamberlain, 1990; but see Hopkins, Bard, et al., 1993). Carrying and leading limb biases appear to be inversely related (Hopkins \& de Waal, 1995), suggesting that they may be complementary in their manifestations. Thus, requiring subjects to maintain an upright or unstable posture may elicit a left-sided postural asymmetry that results in greater use of the limb contralateral to the side of the postural asymmetry for whatever behavior is under investigation.

Finally, reaching from a bipedal posture may alter the motor demands of the task in a way that influences directional hand use. For example, I have observed in my own laboratory that when reaching from a bipedal posture as opposed to a quadrupedal posture, chimpanzees tend to use a pincer grip to retrieve food. Tonooka and Matsuzawa (1995) have reported that pincer grips are more often observed when chimpanzees retrieve food with their right rather than their left hands. Thus, bipedal reaching may result in subjects' preference to use a pincer grip, which also happens to correspond to greater use of the right hand. Additional studies should address this issue.

\section{Manipulation}

Consistent with the prediction by MacNeilage et al. (1987), there appears to be some evidence in support of a right-hand bias in manipulation by chimpanzees (Aruguete et al., 1992). These results are consistent with at least one other report on gorillas (Shafer, 1993). On the basis of the findings by Tonooka and Matsuzawa (1995) and 
Jones-Engel and Bard (1996), manipulation appears to be associated with the type of grip employed for reaching for food. One interpretation of these findings is that the greater the prehension requirements of a given task, the greater the use of the right hand because of the needed control of fine motor movements by the left hemisphere (Bradshaw \& Nettleton, 1981).

\section{Tool Use}

Studies examining hand preferences for tool use have failed to reveal significant population-level hand preferences. This would suggest that the use of tools is neither a sufficient nor a necessary condition for the expression of population-level hand preferences in chimpanzees, a finding that contradicts several evolutionary theories of handedness (Frost, 1980; Kimura, 1979). This conclusion may be premature, because I believe it is important to dissociate the motor demands of the tool-use tasks from the bimanual feeding tasks reported to date in apes and those typically utilized with humans. For measures of bimanual hand use, the two hands are working simultaneously to attain one goal; one hand assumes the supportive role and one assumes the active role. Studies of hand preference and tool use in chimpanzees simply in efforts to collect and analyze data tend to ignore postural or other constraints and collapse the data across all of these conditions. Whether population asymmetries in hand preference are manifest as assessed by tool use without consideration of other bimanual activities warrants further empirical consideration under more constrained observation conditions in which posture is taken into account.

\section{CONCLUSIONS}

In conclusion, population-level handedness is evident in chimpanzees for some behavioral measures. Posture appears to play a significant role in the expression of strength and direction of hand preference. Additionally, examining hand preferences in behavioral contexts in which the left and right hands are free of any locomotor or postural constraints appears to be advantageous in revealing significant lateral biases. Ultimately, the question of what hand-preference measures by way of hemispheric specialization in nonhuman primates will need more considered empirical evaluation (see Ettlinger, 1988). For instance, there is very little published information on the development of handedness and the mechanisms underlying the expression of handedness in chimpanzees and other nonhuman primate species (see Fagot, 1993, and Hopkins \& Bard, 1993b, for reviews). These data are critical in establishing whether homologous or analogous processes account for human and nonhuman primate handedness.

Although chimpanzees and other apes appear to exhibit population-level hand preference for certain tasks, some have argued that this represents "task-specific" rather than "true" handedness, as is the case in humans (McGrew \& Marchant, 1994), or a "weaker" form of handedness (Corballis, 1992). True handedness represents consistent population-level hand preference across a num- ber of different measures of hand use. Few studies have examined intercorrelations in hand use for multiple measures of laterality in chimpanzees. In my own laboratory, we have found that four measures (quadrupedal reaching, bipedal reaching, bimanual feeding, throwing) of hand preferences are positive and significantly correlated with each other, while one measure, coordinated bimanual actions, does not correlate with any of the remaining measures (Hopkins, 1994b). Other scientists have, to a lesser extent, reported similar intercorrelations in hand use between different tasks (Colell et al., 1995a; Sugiyama et al., 1993). Clearly, more research in primates is needed to address this issue, but it should be emphasized that the existence of "true handedness" in humans remains debateable. Recent ethological studies by Marchant and her colleagues (Marchant, McGrew, \& Eibl-Eibesfeldt, 1995; McGrew \& Marchant, 1994) have clearly shown that humans are not as right-handed for all actions as one assumes when reading the literature. Thus, I would argue that science would be better served by comparing human and nonhuman primate handedness on a finite number of tasks - ones that are reliable and that elicit strong lateral bias in both species--rather than on a wide range of tasks.

Most of the studies that have reported population-level handedness in chimpanzees have compared captive and wild apes. This raises the question of whether or not the rearing environment of captive apes influences their hand preference in as yet unspecified ways. For example, McGrew and Marchant (1996) have suggested that (1) raising apes in human environments biases their environment in a way that determines right-handedness, or (2) testing them in captive environments creates "artificial" conditions that allow for expressions of handedness that are not normally present in wild apes. For example, captive chimpanzees often engage in bimanual feeding (Hopkins, 1993), while wild chimpanzees are rarely observed using this feeding strategy (Marchant \& McGrew, 1996).

At present, there is little evidence that raising chimpanzees in human environments causes them to become righthanded. For example, right-sided asymmetries in head orientation (Hopkins \& Bard, 1995), grasping (Fagot \& Bard, 1995), and hand-to-mouth activity (Hopkins \& Bard, 1993a) have been reported in chimpanzees within the first 3 months of life. It is unlikely that external environmental factors can account for these findings. In addition, some of the subjects in studies of captives were wild-caught, and there has been little evidence that their hand-preference patterns differ from those reared in human environments. Finally, concluding that rearing differences may account for the observed differences in handedness in captive and wild apes may be premature, because, as pointed out by Marchant and McGrew (1996), few studies of captive and wild apes have used the same measures and methods of data collection. In the absence of comparable field and captive data, it may not be wise to advocate the role of rearing conditions for lateral bias in apes. In terms of the artificial conditions of the captive environment (point 2 above) and the resulting differences in manifestation and frequency of unbiased hand use, this 
certainly merits consideration in further investigations. Notwithstanding, I do not believe that this diminishes the significance of studies of captive chimpanzees in terms of their application to human handedness.

Finally, right-handedness appears to be more robust in humans than in chimpanzees. For example, the two highest percentages of right-handedness in chimpanzees for any given measure is throwing $(67 \%)$ and coordinated bimanual actions $(67 \%)$, values substantially lower than those reported in humans. In this sense, chimpanzee handedness is weaker than human handedness. The basis for this quantitative difference is not known, but I would speculate that the differences might reflect the role of culture in shaping behavior. What exists in chimpanzees, by way of population-level right-handedness, likely reflects an underlying biological disposition, perhaps due to fetal positions during the third trimester of pregnancy (see Previc, 1991, for a discussion). Human right-handedness may reflect an elaboration of this biological disposition through cultural transmission and modification. An evolved cultural "awareness" of right-handedness in humans would have allowed for the construction of an essentially right-handed world and conformity to this bias.

In conclusion, in this paper, I have focused on specific evolutionary models of hemispheric specialization that emphasize handedness rather than other forms of laterality. Some have argued that hemispheric specialization was evident long before the evolution of handedness (e.g., Hamilton \& Vermeire, 1988), and there is ample evidence of functional asymmetries in many nonprimate species such as birds and rats (Bradshaw \& Rogers, 1993). Thus, the question of whether animals exhibit functional asymmetries seems to no longer be an issue. What remains to be addressed is the degree to which sensory and/or motor processes are lateralized and what similarities and differences exists between species in these domains. Additional research should reveal the complex relationship between evolution, adaptation, and the origin of hemispheric specialization in primates.

\section{REFERENCES}

ANNETT, M. (1985). Left, right, hand, and brain: The right shift theory. London: Erlbaum.

ANNETT, M., \& ANNETT, J. (1991). Handedness for feeding in gorillas. Cortex, 17, 269-276.

Aruguete, M. S., Ely, E. A., \& King, J. E. (1992). Laterality in spontaneous motor activity of chimpanzees and squirrel monkeys. American Journal of Primatology, 27, 177-188.

BECK, B. B. (1980). Animal tool behavior. New York: Garland STM Press.

BoEsCH, C. (1991). Handedness in wild chimpanzees. International Journal of Primatology, 6, 541-558.

Bradshaw, J. L., \& NetTleton, N. C. (1981). The nature of hemispheric specialization in man. Behavioral \& Brain Sciences, 4, 51-91.

BradshaW, J. L., \& Rogers, L. (1993). The evolution of lateral asymmetries, language, tool-use and intellect. San Diego: Academic Press.

Brésard, B., \& Bresson, F. (1983). Handedness in Pongo pygmaeus and Pan troglodytes. Journal of Human Evolution, 12, 659-666.

Byrne, R. W., \& Byrne, J. M. (1991). Hand preferences in the skilled gathering tasks of mountain gorillas (Gorilla gorilla berengei). Cortex, 27, 521-536.
Calvin, W. H. (1983). The throwing madonna: Essays on the brain. New York: Bantam Books.

Chorazyna, H. (1976). Shifts in laterality in a baby chimpanzee. Neuropsychologia, 14, 381-384.

CHRISTEL, M. I. (1994). Grasping techniques and hand preferences in apes and humans. In H. Preuschoft \& D. J. Chivers (Eds.), Hands of primates (pp. 91-108). Vienna: Springer-Verlag.

Colell, M., Segarra, M. D., \& Sabater-Pi, J. (1995a). Hand preferences in chimpanzees (Pan troglodytes), bonobos (Pan paniscus) and orangutans (Pongo pygmaeus) in food-reaching and other daily activities. International Journal of Primatology, 16, 413-434.

Colell, M., Segarra, M. D., \& Sabater-Pi, J. (1995b). Manual laterality in chimpanzees (Pan troglodytes) in complex tasks. Journal of Comparative Psychology, 109, 298-307.

Corballis, M. C. (1989). Laterality and human evolution. Psychological Bulletin, 96, 492-505.

CORBALLIS, M. C. (1992). The lopsided ape: Evolution of the generative mind. New York: Oxford University Press.

Cunningham, D., Forsythe, C., \& WARD, J. P. (1989). A report on behavioral lateralization in an infant orang-utan (Pongo pygmaeus). Primates, 30, 249-253.

Dimond, S., \& Harries, R. (1984). Face touching monkeys, apes, and man: Evolutionary origins and cerebral asymmetry. Neuropsychologia, 22, 227-233.

ETTLINGER, G. (1988). Hand preference, ability, and hemispheric specialization: How far are these factors related in the monkey? Cortex, 24, 389-398.

FAGOT, J. (1993). Ontogeny of object manipulation and manual lateralization in the Guinea baboon: Preliminary observations. In J. P. Ward \& W. D. Hopkins (Eds.), Primate laterality: Current behavioral evidence of primate asymmetries (pp. 235-250). New York: Springer-Verlag.

FAGOT, J., \& BARD, K. A. (1995). Lateralization in the grasping reflex in neonatal chimpanzees. Infant Behavior \& Development, 18, 253-255.

FAGOT, J., DREA, C. M., \& WAllen, K. (1991). Asymmetrical hand use in rhesus monkeys (Macaca mulatta) in tactually-and-visually regulated tasks. Journal of Comparative Psychology, 105, 260-268.

FAGOT, J., \& VAUCLAIR, J. (1988). Handedness and bimanual coordination in Gorilla gorilla. Brain Behavior \& Evolution, 32, 89-95.

FERSTER, C. B. (1957). Concurrent schedules of reinforcement in the chimpanzee. Science, 126, 509.

FinCH, G. (194I). Chimpanzee handedness. Science, 94, 117-118.

Frost, G. T. (1980). Tool behavior and the origins of laterality. Journal of Human Evolution, 9, 447-459.

Gardner, R. A., \& Gardner, B. A. (1968). Teaching sign language to a chimpanzee. Science, 165, 664-672.

Geschwind, N., \& GALABURda, A. M. (1987). Cerebral lateralization: Biological mechanisms, associations and pathology. Cambridge, MA: MIT Press.

GLASER, H. S. R. (1971). Differentiation of scribbling in a chimpanzee. In H. Kummer (Ed.), Proceedings of the Third International Congress of Primatology (pp. 142-149). Basel: S. Karger.

Goodall, J. (1970). Tool use in primates and other vertebrates. In D. S. Lehrman, R. A. Hinde, \& E. Shaw (Eds.), Advances in the study of behavior (pp. 195-249). New York: Academic Press.

GoODall, J. (1986). The chimpanzees of Gombe: Patterns in adaptation. Cambridge, MA: Harvard University Press.

GrZimeK, D. (1949). Rechts- und Linkshandigkeit bei Pferden, Papageien und Affen [Right- and left-handedness in horses, parrots, and apes]. Zeitscrift für Tierpsychologie, 6, 405-432.

Hamilton, C. R., \& Vermeire, B. A. (1988). Cognition, not handedness, is lateralized in monkeys. Behavioral \& Brain Sciences, 11, 722-725.

HarRIS, L. J. (1993). Handedness in apes and monkeys: Some views from the past. In J. P. Ward \& W. D. Hopkins (Eds.), Primate laterality: Current behavioral evidence of primate asymmetries (pp. 1-41). New York: Springer-Verlag.

Healey, J. M., Liederman, J., \& Geschwind, N. (1986). Handedness is not a unidimensional trait. Cortex, 22, 33-53.

HEESTAND, J. (1986). Behavioral lateralization in four species of apes? Unpublished doctoral dissertation, University of Washington.

HELLIGE, J. B. (1993). Hemispheric asymmetry: What's right and what's left. Cambridge, MA: Harvard University Press. 
Hewes, G. (1973). Gestural origins model of language. Current Anthropology, 88, 123-150.

HoPKINS, W. D. (1993). Posture and reaching in chimpanzees (Pan) and orangutans (Pongo). Journal of Comparative Psychology, 17, 162-168.

HopKINS, W. D. (1994a). Hand preferences for bimanual feeding in 140 captive chimpanzees (Pan troglodytes): Rearing and ontogenetic factors. Developmental Psychobiology, 27, 395-407.

Hopkins, W. D. (1994b). Multiple measures of handedness in chimpanzees (Pan): Between- and within-subject variability. American Journal of Primatology, 33, 215.

HoPKINS, W. D. (1995a). Hand preferences for a coordinated bimanual task in 110 chimpanzees (Pan troglodytes): Cross-sectional analysis. Journal of Comparative Psychology, 109, 291-297.

HoPKINS, W. D. (1995b). Hand preferences in juvenile chimpanzees: Continuity in development. Developmental Psychology, 31, 619-625.

HoPKINS, W. D., \& BARD, K. A. (1993a). Hemispheric specialization in infant chimpanzees (Pan troglodytes): Evidence for a relation between gender and arousal. Developmental Psychobiology, 26, 219-235.

HOPKINS, W. D., \& BARD, K. A. (1993b). The ontogeny of hemispheric specialization in nonhuman primates with special reference to chimpanzees. In J. P. Ward \& W. D. Hopkins (Eds.), Primate laterality: Current behavioral evidence of primate asymmetries (pp. 251-266). New York: Springer-Verlag.

HOPKINS, W. D., \& BARD, K. A. (1995). Evidence of asymmetries in spontaneous head turning in infant chimpanzees (Pan troglodytes). Behavioral Neuroscience, 109, 808-812.

Hopkins, W. D., Bard, K. A., Jones, A., \& Bales, S. (1993). Chimpanzee hand preference for throwing and infant cradling: Implications for the origin of human handedness. Current Anthropology, 34, 786-790.

Hopkins. W. D., BenNett, A., Bales, S., LeE, J., \& Ward, J. P. (1993) Behavioral laterality in captive bonobos (Pan paniscus). Journal of Comparative Psychology, 107, 403-410.

HoPKINS, W. D., \& DE WAAL, F. D. (1995). Behavioral laterality in captive bonobos (Pan paniscus): Replication and extension. International Journal of Primatology, 16, 261-276.

HoPKINs, W. D., \& MorRIs, R. D. (1993). Handedness in great apes. A review of findings. International Journal of Primatology, 14, 1-25.

JONES-ENGEL, L. E., \& BARD, K. A. (1996). Grip type and hand preference in young chimpanzees. American Journal of Primatology, 39, 1-15.

KimURA, D. (1979). Neuromotor mechanisms in the evolution of human communication. In H. D. Steklis \& M. J. Raleigh (Eds.), Neurobiology of social communication in primates (pp. 197-219). San Diego: Academic Press.

KING, J., \& LANDAU, V. (1993). Manual preferences in varieties of reaching in squirrel monkeys. In J. P. Ward \& W. D. Hopkins (Eds.), Primate laterality: Current behavioral evidence of primate asymmetries (pp. 107-124). New York: Springer-Verlag.

MacNeilage, P. F. (1991). The "postural origins" theory of primate neurobiological asymmetries. In N. A. Krasnegor, D. M. Rumbaugh, R. L. Schiefelbusch, \& M. Studdert-Kennedy (Eds.), Biological and behavioral determinants of language development (pp. 165-188). Hillsdale, NJ: Erlbaum.

MacNeilage, P. F., Studdert-Kennedy, M. G., \& Lindblom, B. (1987). Primate handedness reconsidered. Behavioral \& Brain Sciences, 10, 247-303.

Manning, J. Y., \& Chamberlain, A. T. (1990). The left-sided cradling preference in great apes. Animal Behavior, 39, 1224-1227.

MARCHANT, L. F. (1983). Hand preference among captive island groups of chimpanzees (Pan troglodytes). Unpublished doctoral dissertation, Rutgers University.

Marchant, L. F., \& MCGrew, W. C. (1991). Laterality of function in apes: A meta-analysis of methods. Journal of Human Evolution, 21 , 425-438.

Marchant, L. F., \& MCGrew, W. C. (1996). Laterality of limb function in wild chimpanzees of Gombe National Park: Comprehensive study of spontaneous activities. Journal of Human Evolution, 30, 427-443.

Marchant, L. F., McGrew, W. C., \& Eibl-Eibesfeldt, I. (1995). Is human handedness universal? Ethological analyses from three traditional cultures. Ethology, 101, 239-258.
Marchant, L. F., \& Steklis, H. D. (1986). Hand preference in a captive island group of chimpanzees (Pan troglodytes). American Journal of Primatology, 10, 301-313.

McGrew, W. C., \& Marchant, L. F. (1992). Chimpanzecs, tools, and termites: Hand preference or handedness? Current Anthropology, 33, 114-119.

MCGrew, W. C., \& Marchant, L. F. (1994). Primate ethology: A perspective on human and nonhuman handedness. In P. K. Bock (Ed.), Handbook of psychological anthropology (pp. 171-184). Westport, CT: Greenwood Press.

MCGrew, W. C., \& Marchant, L. F. (1996). On which side of the apes? Ethological study of laterality of hand use. In W. C. McGrew, L. F. Marchant, \& T. Nishida (Eds.), Great ape societies (pp. 255-272). Cambridge, MA: Cambridge University Press.

MorRis, R. D., Hopkins, W. D., Bolser-Gilmore, L. (1993). Assessment of hand preference in two language-trained chimpanzees ( $P a n$ troglodytes): A multimethod analysis. Journal of Clinical \& Experimental Neuropsychology, 15, 487-502.

Nishida, T., \& Hiraiwa, M. (1982). Natural history of a tool-using behavior in wild chimpanzees in feeding upon wood-boring ants. Journal of Human Evolution, 11, 73-99.

Olson, D. A., Ellis, J. E., \& NADler, R. D. (1990). Hand preferences in captive gorillas, orang-utans, and gibbons. American Journal of Primatology, 20, 83-94.

O’Neil, C. R., Stratton, H. T. R., Ingersoll, R. H., \& Fouts, R. (1978). Conjugate lateral eye movements in Pan troglodyles. Neuropsychologia, 16, 759-762.

PREMACK, D. (1970). Language in a chimpanzee? Science, 172, 808-822.

Previc, F. H. (1991). A general theory concerning the prenatal origins of cerebral lateralization in humans. Psychological Review, 98. 299-334.

Ramsay, D. S., \& Weber, S. L. (1986). Infants' hand preference in a task involving complementary roles of the two hands. Child Development, 57, 300-307.

RaSMUSSEN, T., \& MiLneR, B. (1977). The role of early left-brain injury in determining lateralization of cerebral speech functions (Annals of the New York Academy of Sciences, Vol. 299, pp. 355-369). New York: New York Academy of Sciences.

RoBInson, C. (1979). The development of hand preference in children and young chimpanzees. Unpublished doctoral dissertation, University of Nevada, Reno.

RoNey, L. S., \& KING, J. E. (1993). Postural effects on manual reaching laterality in squirrel monkeys (Saimiri sciureus) and cotton-top tamarins (Saguinus oedipus). Journal of Comparative Psychology, 107, 380-385.

Rumbaugh, D. M. (1977). Language learning by a chimpanzee: The LANA project. New York: Academic Press.

Savage-Rumbaugh, E. S. (1986). Ape language: From conditioned response to symbol. New York: Columbia University Press.

Shafer, D. D. (1993). Patterns of hand preference in gorillas and children. In J. P. Ward \& W. D. Hopkins (Eds.), Primate laterality: Current behavioral evidence of primate asymmetries (pp. 267-283). New York: Springer-Verlag.

Steiner, S. M. (1990). Handedness in chimpanzees. Friends of Washoe, 9, 9-19.

Steklis, H. D., \& Raleigh, M. J. (EDs.) (1979). Neurohiology of social communication in primates. San Diego: Academic Press.

Suarez, S. D., \& Gallup, G. G. (1986). Face touching in primates: A closer look. Neuropsychologia, 24, 597-600.

Sugiyama, Y., Fushimi, T., Sakura, O., \& Matsuzawa, T. (1993). Hand preference and tool use in wild chimpanzees. Primates, 34, 151-159.

TONOOKA, R., \& MATSUZAWA, T. (1995). Hand preferences in captive chimpanzees (Pan troglodytes) in simple reaching for food. International Journal of Primatology, 16, 17-35.

TutTlE, R. H. (1986). Apes of the world: Their social behavior, communication, mentality, and ecology. Park Ridge, NJ: Noyes Publications.

Ward, J. P., \& Hopkins, W. D. (1993). Primate laterality: Current behavioral evidence of primate asymmetries. New York: SpringerVerlag. 
Ward, J. P., Milliken, G. W., \& Stafford, D. K. (1993). Patterns of lateralized behavior in prosimians. In J. P. Ward \& W. D. Hopkins (Eds.), Primate laterality: Current behavioral evidence of primate asymmetries (pp. 43-76). New York: Springer-Verlag.

WARREN, J. M. (1980). Handedness and laterality in humans and other animals. Physiological Psychology, 8, 351-359.

WeLLES, J. F. (1976). A comparative study of prehension in anthropoids. Saugetierkundliche Mitteilungen, 24, 26-37.

WUNDRUM, I. J. (1986). Cortical motor asymmetries and Hominid feeding strategies. Human Evolution, 1, 183-188.

Yeni-Komshian, G. H., \& Benson, D. A. (1976). Anatomical study of cerebral asymmetry in the temporal lobe of humans, chimpanzees and monkeys. Science, 192, 387-389.
Yerkes, R. (1927). The mind of the gorilla. Genetic Psychology Monographs, 2, 1-193.

\section{NOTE}

1. Handedness indices are calculated using the formula (\#Rreaches \#Lreaches)/(\#Rreaches + \#Lreaches). The resulting value ranges from 1.0 to -1.0 , with positive values reflecting right-hand biases and negative values reflecting left-hand biases. The absolute value reflects the strength in hand preference.

(Manuscript received October 10, 1995; revision accepted for publication May 9, 1996.) 